\title{
РОЖДАЕМОСТЬ В ПОВТОРНЫХ СОЮЗАХ В РОССИИ: ПОЗВОЛЯЕТ ЛИ ВСТУПЛЕНИЕ В НОВЫЙ СУПРУЖЕСКИЙ СОЮЗ ДОСТИЧЬ ИДЕАЛА ДВУХДЕТНОЙ СЕМЬИ?
}

\author{
СЕРГЕЙ ЗАХАРОВ 1 , ЕЛЕНА ЧУРИЛОВА², ВИКТОР АГАДЖАНЯН ${ }^{3}$
}

\begin{abstract}
Быстрая деинституционализачия семьи в развитых странах во второй половине ХХ века привела к тому, что в общественном сознании стали приемлемыми различные формы семьи, и, в частности, незарегистрированные сожительства стали иироко распространенной формой супружеских союзов, дополняющих традииионный брак. Кроме того, наблюдается как рост вероятности распада первого брачно-партнерского союза, так и увеличение шансов вступления во второй и последуюший союзы. Демографические последствия этих фундаментальных сочиальных сдвигов, в частности рождаемость в повторных союзах и ее вклад в итоговую рождаемость поколений, мало изучены 6 России. В данной статье для характеристики рождаемости в повторных союзах (браках $и$ сожительствах) для послевоенных поколений россиян используются данные лонгитюдного исследования «Родители и дети, мужчины и женщины в семье и обществе», выполненного в рамках международного проекта ЕЭК ООН «Поколения и гендер». Статья вносит вклад в дискуссию о сохраняющемся идеале двухдетной модели семьи в Европе и показывает, в какой степени рождение детей в повторных союзах способствует поддержанию этого идеала в России.
\end{abstract}

Результаты проведенного исследования показывают, что повторные союзы играют важную роль 8 реализации репродуктивных установок. Вклад рождений в повторных союзах в общее число рождений непрерывно увеличивался в рассматриваемый период 1950-2009 г2. Вступление в повторный союз позволяет компенсировать дефищит рождений, возникающий на предразводной и послеразводной стадиях. Повторные союзы часто не регистрируются официально, однако, это не мешает супругам реализовывать свои репродуктивные намерения. Вступление 6 незарегистрированный повторный союз, так же, как и в зарегистрированный, повышает для женщины вероятность иметь двоих и более детей, тем самым обеспечивая возможность соответствовать сочиальной норме двухдетной семьи. Поэтому успешность поиска нового партнера для женщины репродуктивного возраста является ключевым фактором, определяютим число детей, которое она может родить.

Ключевые слова: брак, сожительство, повторные супружеские союзы, рождаемость, двухдетный идеал, поколения, выборочное исследование «Родители и дети, мужчины и женщины в семье и обществе», проект ЕЭК ООН «Поколения и Гендер».

\footnotetext{
${ }^{1}$ НАЦИОНАЛЬНЫЙ ИССЛЕДОВАТЕЛЬСКИЙ УНИВЕРСИТЕТ «ВЫСШАЯ ШКОЛА ЭКОНОМИКИ» (РОССИЯ); 2 РОССИЙСКАЯ ЭКОНОМИЧЕСКАЯ ШКОЛА (РОССИЯ); 3 УНИВЕРСИТЕТ КАНЗАСА (США).

*E-mail: szakharov@hse.ru

СТАТЬЯ ПОСТУПИЛА В РЕДАКЦИЮ В ДЕКАБРЕ 2015 Г.

В ИССЛЕДОВАНИИ ИСПОЛЬЗОВАНЫ РЕЗУЛЬТАТЫ ПРОЕКТА № $14-05-0055$ «ИЗУЧЕНИЕ ДИНАМИКИ ФОРМИРОВАНИЯ И РАЗВИТИЯ СЕМЕЙ И ПРОЦЕССОВ РОЖДАЕМОСТИ НА ДАННЫХ ВЫБОРОЧНЫХ ОБСЛЕДОВАНИЙ» ПО КОНКУРСУ ИССЛЕДОВАТЕЛЬСКИХ ПРОЕКТОВ НАУЧНО-УЧЕБНЫХ ГРУПП ПРОГРАММЫ «НАУЧНЫЙ ФОНД НИУ ВШЭ».
} 


\section{КОМПЕНСИРУЮЩАЯ РОЛЬ ПОВТОРНЫХ СОЮЗОВ}

Быстрая деинституционализация семьи в развитых странах во второй половине XX века привела к тому, что в общественном сознании стали приемлемыми различные формы семьи, будь то традиционный брак, незарегистрированные сожительства, материнские семьи или LAT-партнерства ${ }^{1}$ [Голод 1998; Гурко 2003; 2008].

В развитых странах наблюдается как увеличение вероятности распада первого брака, так и увеличение шансов вступления во второй и последующий союзы. С.И. Голод в свое время справедливо заметил, что: «Говоря общо, возникновение любых альтернатив можно рассматривать как вызов неравенству. По-видимому, в нашем конкретном случае неравноправие полов привело к прорыву самовыражения и как одному из его последствий - формированию альтернативных (классической моногамии) браков» [Голод 1998: 211].

Демографические последствия этих фундаментальных социальных сдвигов, в частности рождаемость в повторных союзах и ее вклад в итоговую рождаемость, мало изучены в России, что особенно очевидно на фоне нарастающего бума исследований данного вопроса за рубежом [Vikat et al. 1999; Prskawetz et al. 2003; Henz, Thomson 2004; Thomson et al. 2014; Kreyenfeld, Heintz-Martin 2015].

Как и в других развитых странах, в России вступление в повторный брачнопартнерский союз после распада первого широко распространилось в послевоенных поколениях. Такая тенденция отмечалась еще в работах В.А. Беловой, Л.Е. Дарского, М.С. Тольца и других исследователей в 1980-е годы [Тольц 1986b; Белова 1983; Белова, Дарский 1987; Вишневский, Тольц 1988]. Складывающаяся ситуация была тогда подробно проанализирована в пионерной для отечественной демографии статье В.А. Беловой и Е.М. Моревой, опубликованной в 1988 г. и базирующейся на результатах анализа данных больших выборочных обследований ЦСУ СССР 1978 и 1981 гг. [Белова, Морева 1988].

Есть все основания утверждать, что в России от поколения к поколению происходило повышение вероятности развода, особенно в молодых репродуктивных возрастах, что увеличивало шансы на создание новой семьи и появление детей в них, и в первую очередь для женщины, даже при наличии у нее детей от предыдущего брака [Белова 1983; Белова, Дарский 1987]. Степень компенсации распавшихся браков повторными союзами росла не только за счет формальных, но, и даже в большей степени, за счет неформальных союзов, меньшая часть из которых когда-либо конвертируется в зарегистрированный брак [Захаров 2007a; 2007b; 2009]. В связи с тем, что демографическая роль устойчивых сожительств (неформальных, незарегистрированных, «бракоподобных» союзов совместно проживающих партнеров) сегодня очень велика и продолжает увеличиваться и не только для первых, но и еще более значимо для повторных союзов,

\footnotetext{
${ }^{1}$ LAT - “Live Apart Together” ("быть вместе, проживая раздельно”) - распространившееся с середины 1970-х годов в средствах массовой информации и в научной литературе понятие, призванное определять ситуации, в которых партнеры поддерживают устойчивые отношения, но не проживают совместно в одном домохозяйстве. Как правило, речь идет о партнерах, не состоящих в официальном браке, но это не обязательное условие. LAT-отношения для состоящих в зарегистрированном браке также возможны. В этих союзах также могут быть или не быть дети (см: [Levin 2004]). «Гостевой брак» оказывается наиболее близким LAT и более распространенным понятием в отечественной литературе.
} 
имеет смысл рассматривать первые и повторные союзы всех типов (формальных и неформальных) совместно и не ограничиваться только зарегистрированными браками.

Согласно нашим оценкам, основанным на данных выборочного лонгитюдного обследования «Родители и дети, мужчины и женщины в семье и обществе» (РиДМиЖ) 2 , половина мужчин и женщин среди тех, чей первый союз распался, вступили в новый брачно-партнерский союз в течение 3-5 лет после расставания с первым партнером; в течение 15 лет после окончания первого союза нашли нового партнера 80\% мужчин и 70\% и женщин [Захаров 2009]. По данным другого выборочного исследования, проведенного Росстатом, доля женщин, состоящих в повторном супружеском союзе, среди всех женщин, состоящих в союзах, составляет $12,2 \%$ среди $25-29$-летних, $20 \%$ среди $30-34$-летних и $27 \%$ среди женщин в возрасте 35-39 лет [Аналитический отчет... 2013].

Средний интервал времени между окончанием первого союза и началом второго непрерывно сокращается после Второй мировой войны: для первых союзов, распавшихся в 1950-х-1960-х годах, он составлял 5 лет, тогда как в настоящее время он равен 4 годам [Белова, Морева 1988; Захаров 2009].

Среди повторных союзов доля незарегистрированных (сожительств) продолжает увеличиваться: за последние десятилетия при сопоставимом общем уровне компенсации распада семьи новым союзом доля вступивших в неформальные союзы возросла в несколько раз. Так, среди женщин, разведенных в 1970-е годы, 50\% вступили в официальный брак, а 12\% - в неформальный союз. Среди женщин, разведенных в первой половине 1990-х годов, 30\% живут в повторном официальном браке и еще 30\% - в незарегистрированных сожительствах [Захаров 2009]. Согласно Выборочному наблюдению репродуктивных планов населения в 2012 г., для 42\% женщин, вступивших в повторный брак после достижения 25-летнего возраста, этот брак является незарегистрированным. Регистрацию повторного супружеского союза, по данным того же исследования, считают обязательной $28,4 \%$ женщин и $24,6 \%$ мужчин, желательной - 53,9 и $49,3 \%$ женщин и мужчин соответственно, а нежелательной - 17,7 и 26,1\%. При этом отношение к регистрации повторного брака не зависит от возраста [Аналитический отчет... 2013]. Сходное отношение к регистрации повторного брака фиксируют и локальные исследования [Архангельский 2005: 67-68].

\footnotetext{
2 Обследование «Родители и дети, мужчины и женщины в семье и обществе» (РиДМиЖ/RusGGS) является частью международного исследовательского проекта сравнительных исследований «Generations and Gender Programme» / «Программа поколения и гендер», координатором которого выступает Европейская экономическая комиссия ООН при поддержке международного консорциума научно-исследовательских центров (см: http://www.unece.org/ead/pau/ggp/Welcome.html). Всего в России было проведено три волны опроса в 2004, 2007 и 2011 гг., в ходе каждой из которых было опрошено более 11 тыс. респондентов обоего пола в возрасте 18 лет и старше (панельная составляющая опрошенных повторно в 2007 и 2011 г. - более 7 тыс.), представляющих городское и сельское население 32 субъектов Российской Федерации, включая Москву и Санкт-Петербург. В России исследование РиДМиЖ/RusGGS координировалось Независимым институтом социальной политики/НИСП (Москва), директор программы - О.В. Синявская, научный руководитель - С.В. Захаров. Полевая часть исследования проведена Независимой исследовательской группой «Демоскоп» (руководители - П.М. Козырева и М.С. Косолапов) при финансовой поддержке Пенсионного фонда Российской Федерации, Научного Общества Макса Планка (Германия), Сбербанка и др. Дополнительную информацию о проекте, публикациях см: http://www.socpol.ru/research_projects/proj12.shtml.
} 
Тенденция увеличения доли мужчин и женщин, вступающих в повторный союз после распада первого, имела следствием рост суммарного времени жизни в брачнопартнерских союзах [Захаров 2007a; 2007b], что, согласно исследованиям, выполненным на европейских данных, для женщин выражается в увеличении итоговой рождаемости [Beaujouan, Solaz, 2008; Thomson et al. 2009; Thomson et al. 2014].

Оценки, выполненные нами на данных трех волн РиДМиЖ (2004, 2007, 2011 гг.), показывают, что в России вероятность рождения второго ребенка в повторном союзе значимо не отличается от таковой в непрерывном первом союзе. Этот неординарный факт отечественные исследователи обнаружили еще три десятилетия назад, когда приоткрывалась завеса неизвестности в отношении российских тенденций рождаемости в повторных браках ${ }^{3}:$ «В тех группах населения, где уже давно и стабильно существует низкий уровень рождаемости, женщины молодых возрастов, состоящие в повторном браке, родили к моменту обследования в среднем несколько больше детей, чем состоящие в 1-ом браке. Поскольку у этих женщин заметно выше вероятность рождения второго ребенка (что соответствует довольно часто встречающемуся в литературе предположению, что многие из женщин, вступающих в повторный брак, рожают второго ребенка, не откладывая), можно полагать, что в этих группах населения повторные браки стимулируют рождение второго ребенка. Однако даже в этих группах населения среднее ожидаемое число детей у женщин, состоящих в повторном браке, либо практически не отличается от среднего ожидаемого числа детей у женщин, состоящих в первом браке, либо немного ниже его» [Белова 1983: 15-16]. В более поздней обобщающей работе, основанной на тех же данных масштабных выборочных исследований ЦСУ СССР в 1978 и 1981 гг., В.А. Белова и Л.Е. Дарский приводят оценки итоговой рождаемости для женщин, состоящих в первых и в повторных браках к моменту опроса, отраженные в таблице 1.

Произведя сравнения в разрезе различных социально-демографических групп населения, авторы приходят к выводу, что в социальных и этнодемографических группах, характеризующихся низкой рождаемостью (в первую очередь среди городских жителей, лиц с высоким образованием), «влияние распадения браков вследствие развода и овдовения на среднее число детей оказалось незначительным и зависящим от степени компенсации повторными браками разводов и овдовений» [Белова, Дарский 1987: 43].

\footnotetext{
${ }^{3}$ В начале 1980-х годов В.А. Белова следующим образом описывала дискуссию среди специалистов: «В настоящее время существуют разные мнения по вопросу об уровне рождаемости в повторных браках. Одни исследователи считают, что те женщины, которые вступают в брак вторично, имеют в среднем меньше детей, чем состоящие в непрерывном первом браке, поскольку неизбежен перерыв в брачной жизни, а неудавшийся первый брак накладывает свой отпечаток на репродуктивное поведение женщины в повторном браке. Другое мнение прямо противоположно: повторные браки считаются стимулом к рождению еще одного ребенка от второго брака, а вместе с детьми, уже рожденными в первом браке, женщины, состоящие в повторном браке, имеют в среднем детей больше, чем женщины в первом браке» [Белова 1983: 15]. См. также: [Тольц 1986а: 49-53]. По сути, те же вопросы остаются в центре внимания и современных исследователей в России и за рубежом.
} 
Таблица 1. Среднее число детей, рожденных женщинами, вступившими в первый брак в разные годы, в зависимости от того, состоят ли они в первом или в повторном браке к моменту опроса (по данным обследования ЦСУ СССР в 1981 г.)

\begin{tabular}{c|c|c|c}
\hline Год вступления в & \multicolumn{2}{|c|}{ Состоят в браке: } & \multirow{2}{*}{ Разница } \\
\cline { 2 - 3 } первый брак & в первом & в повторном & 0,71 \\
$1945-1949$ & 2,98 & 2,27 & 0,62 \\
$1950-1954$ & 2,75 & 2,13 & 0,55 \\
$1955-1959$ & 2,64 & 2,09 & 0,35 \\
$1960-1964$ & 2,37 & 2,03 & 0,29 \\
$1965-1969$ & 2,19 & 1,90 & 0,19 \\
$1970-1974$ & 1,85 & 1,66 & $-0,01$ \\
$1975-1979$ & 1,23 & 1,24 & \\
\hline
\end{tabular}

Источник: [Белова, Дарский 1987: 40].

В современной России вступление в повторные союзы компенсирует половину распавшихся первых союзов. Вступление в повторный союз происходит в более короткие сроки, чем это было несколько десятилетий назад, и все чаще в границах репродуктивного возраста, что дает основание предполагать увеличение вероятности рождения ребенка в повторных союзах. Несмотря на возросшую нестабильность брачно-партнерских союзов и увеличившуюся вероятность их распада, средняя длительность периода, в течение которого возможна беременность и рождение ребенка (с учетом повторных союзов), не уменьшается и, более того, вообще мало менялась в женских поколениях 1930-1960-х годов рождения [Захаров 2007a; 2007b].

Таким образом, мы можем сформулировать следующие исследовательские гипотезы.

- Вероятность рождения ребенка в повторных союзах имеет тенденцию к увеличению.

- Вклад повторных союзов в рождения детей всех очередностей, особенно вторых и последующих, растет.

- Большинство рождений в повторных союзах будут с формальной точки зрения «внебрачными», т.е. рожденными партнерами, не состоящими в зарегистрированных браках.

В настоящей статье проанализирована рождаемость в повторных союзах на основе данных всех трех волн репрезентативного панельного исследования РиДМиЖ. Выборка каждой волны исследования содержит данные о более чем 11000 мужчинах и женщинах старше 18 лет, из них более 7000 респондентов были опрошены во всех трех волнах исследования. Для анализа данных из панельной части исследования отобрана подвыборка женщин 1930-1986 годов рождения (N=3693).

\section{ИДЕАЛ ДВУХДЕТНОЙ СЕМЬИ СРЕДИ РОССИЯН СОХРАНЯЕТСЯ}

Желаемое число детей в семье - число детей, которое индивид или семья хотели бы иметь при наличии всех необходимых для этого условий. Считается общепризнанным, что при всех ограничениях и недостатках этот индикатор наилучшим образом характеризует потенциал рождаемости на индивидуальном уровне, а в качестве средней величины для всего населения - социальную норму детности, подталкивающую индивида к реализации 
репродуктивных установок [Архангельский 2005: 49-50; 2006: 54-59; Зверева 2012: 43-44; Günther, Harttgen 2016]. Показатель среднего желаемого числа детей на протяжении длительного периода времени, измеряемого несколькими десятилетиями, и для мужчин, и для женщин принимал значения, близкие к 2 , и данная ситуация практически не отличается от ситуации в других развитых странах, где также распространен идеал двухдетной семьи [Thomson 2004; Testa 2012].

Согласно опросам ВЦИОМ, проводившимся на протяжении 1990-х годов, желаемое число детей в 1991 г. составляло 2,25, в 2000 г. - 2,12, а значимые возрастные различия мнений о желаемом числе детей в семье отсутствовали. Кроме того, не было различий в потенциальной рождаемости для состоящих в браке, разведенных и вдовых женщин [Бодрова 2002].

Среднее желаемое число детей по данным РиДМиЖ-2007 составило 2,06, по данным РиДМиЖ-2011 - 2,15 среди женщин и 2,18 среди мужчин, по данным исследования «Человек, семья, общество» в 2013 г. - 2,13 среди женщин и 2,09 среди мужчин [Тындик 2012; Малева, Тындик 2014].

Таблица 2. Распределение женщин 18-49 лет по желаемому числу детей, РиДМиЖ2007, 2011, \%

\begin{tabular}{|c|c|c|c|c|c|c|c|}
\hline \multirow{2}{*}{ Число детей } & \multicolumn{7}{|c|}{ Возраст, лет } \\
\hline & $18-19$ & $20-24$ & $25-29$ & $30-34$ & $35-39$ & $40-44$ & $45-49$ \\
\hline \multicolumn{8}{|c|}{ РиДМиЖ-2007 } \\
\hline 0 & 0,9 & 1,8 & 1,2 & 0,7 & 2,3 & 4,7 & 6,2 \\
\hline 1 & 21,5 & 20,6 & 15,4 & 12,9 & 19,7 & 19,2 & 16,8 \\
\hline 2 & 62,8 & 60,0 & 62,9 & 63,5 & 56,3 & 53,1 & 52,0 \\
\hline 3 & 10,3 & 15,0 & 16,8 & 18,3 & 18,1 & 19,2 & 18,1 \\
\hline 4 и более & 4,5 & 2,7 & 3,7 & 4,5 & 3,5 & 3,9 & 6,8 \\
\hline Среднее желаемое число детей & 1,99 & 1,99 & 2,07 & 2,15 & 2,02 & 2,01 & 2,10 \\
\hline \multicolumn{8}{|c|}{ РиДМиЖ-2011 } \\
\hline 0 & 1,3 & 1,3 & 1,3 & 2,5 & 5,4 & 4,9 & 6,9 \\
\hline 1 & 16,9 & 17,8 & 17,2 & 19,2 & 16,7 & 22,8 & 23,6 \\
\hline 2 & 57,5 & 62,8 & 57,7 & 55,5 & 52,5 & 53,7 & 45,9 \\
\hline 3 & 19,4 & 16,1 & 19,3 & 18,6 & 19,6 & 14,4 & 17,5 \\
\hline 4 и более & 5,0 & 2,0 & 4,5 & 4,3 & 5,7 & 4,1 & 6,1 \\
\hline Среднее желаемое число детей & 2,08 & 2,00 & 2,11 & 2,06 & 2,04 & 1,91 & 1,92 \\
\hline
\end{tabular}

Источник: расчеты авторов на основе полных выборок РиДМиЖ-2007, 2011, в которых вопрос о желаемом числе детей задавался идентичным образом.

Сравнение возрастного распределения женщин репродуктивного возраста по желаемому числу детей показывает, что возрастные различия мнений о желаемом числе детей минимальны (таблица 2). Вне зависимости от возрастной категории модальное значение желаемого числа детей в семье по мнению женщин равно 2. Среднее желаемое число детей у женщин разного возраста также близко к двум детям. Таким образом, двухдетная семья остается идеалом для россиян.

В какой мере россиянки следуют социальной норме, показывает рисунок, на котором представлены распределения матерей (женщин, родивших когда-либо одного ребенка) по итоговому числу рожденных детей для условных и реальных поколений к концу детородного периода. Панель, представляющая оценки для календарных лет (для условных поколений), дает ожидаемое распределение для женских поколений, входящих в 
репродуктивный возраст (достигших 15 лет) в некотором календарном году, если на протяжении всего репродуктивного периода для них будет поддерживаться интенсивность рождений детей каждой очередности, наблюдаемая в этом году. Так, если бы рождаемость сохранялась неизменной на уровне первой половины 1980-х годов, то каждая вторая мать имела бы в итоге два рождения. С начала 1990-х годов ожидаемая доля двухдетных матерей установилась на уровне 40\% (последние данные за 2014 г.). Панель, представляющая оценки для реальных поколений по году рождения женщин, дает более сглаженную, но в целом ту же картину. В поколениях, родившихся в начале 1960-х годов, фактическая доля матерей с итоговыми двумя рождениями была на уровне 50\%, а в поколениях 1970-х и 1980х годов рождения с высокой вероятностью можно ожидать $40 \%$.
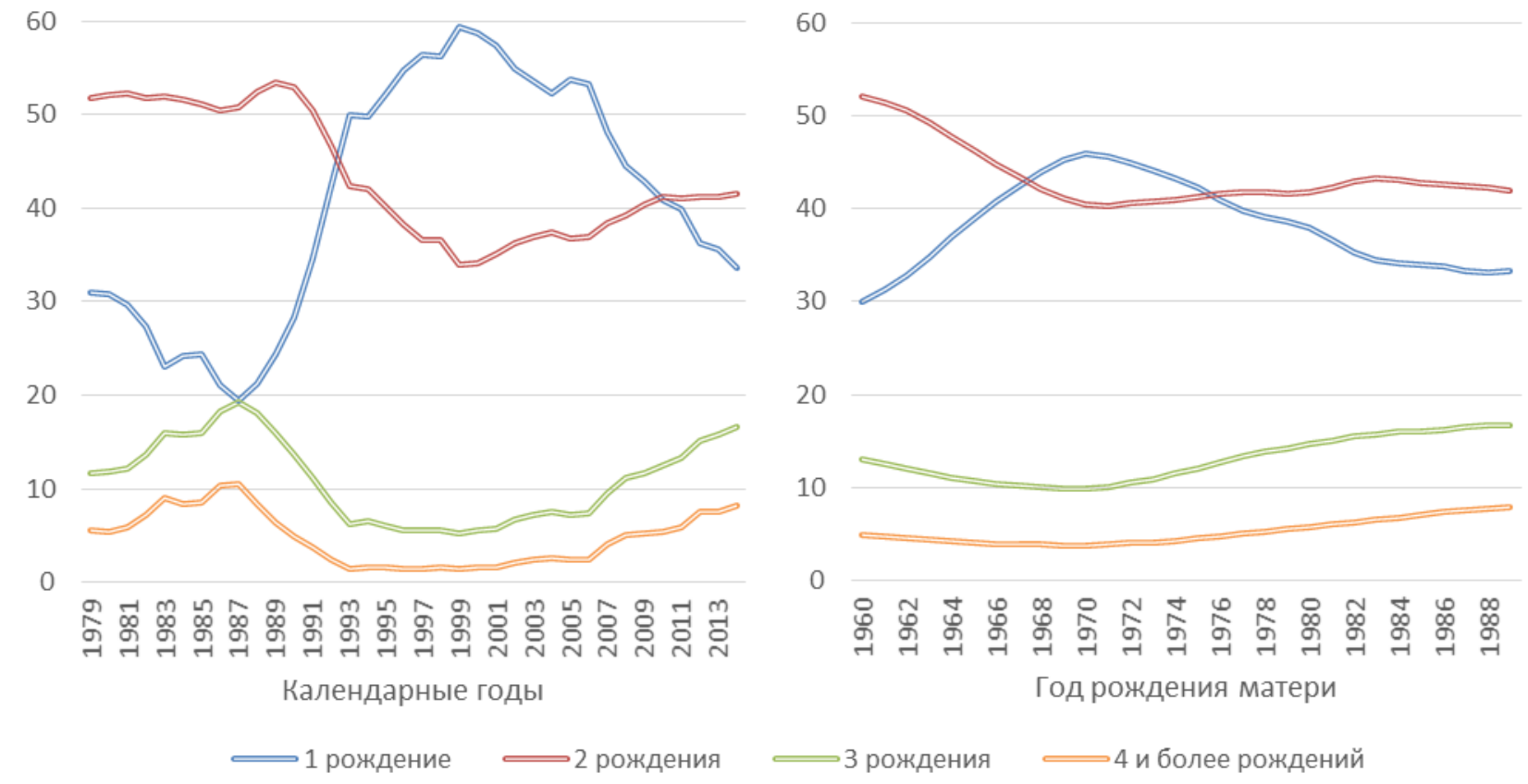

\title{
Рисунок 1. Распределение матерей (женщин, когда-либо родивших живого ребенка) по числу рожденных детей к возрасту 50 лет в России, \%
}

\begin{abstract}
Левая панель - распределение для условных поколений (календарных лет): 1979-2014 г2.
Правая панель - распределение для реальных поколений женщин 1960-1989 годов рождения: фактическое и экстраполированное для когорт, не достигших 50 лет.
\end{abstract}

Источник: Специильные таблицы рождаемости с учетом очередности рождения для условных и реальных поколений, построенные С.В. Захаровым на основе неопубликованных данных Росстата о ежегодных числах зарегистрированных рождений, распределенных по возрасту матери и очередности рождения.

Ожидаемые распределения по числу рожденных детей для условных поколений женщин, оцененные для 1990-х годов, давали основания усомниться, что в российском населении сохраняется двухдетный идеал семьи. Комментариям на тему перехода в России от двухдетного идеала к «однодетному» и, возможно, к «бездетному» несть числа в те годы ${ }^{4}$.

\footnotetext{
${ }^{4}$ См., например, материалы Круглого стола в Институте философии РАН (1998): [Борисов 2007: 658-682]. 
Действительно, ожидаемая доля окончательно однодетных матерей превысила $50 \%$ в 1990-х годах, в то время как ожидаемая доля двухдетных едва достигала 40\%. Однако оценки для реальных поколений свидетельствуют, что двухдетный идеал для семьи в условиях социально-экономической нестабильности все-таки устоял, хотя и был сильно поколеблен фактическими результатами репродуктивной деятельности женщин, родившихся в конце 1960-х - начале 1970-х годов. Среди них доля матерей, имевших только одно рождение, превысила $40 \%$ и даже стала чуть выше доли матерей с двумя рождениями. Но в последующих поколениях доля матерей с двумя детьми вновь устойчиво доминирует над однодетными матерями.

Итак, не только в идеальных представлениях россиян господствуют предпочтения иметь двоих детей, но и на практике большинству женщин, создавших семью, удается следовать социальной норме, разделяемой большинством.

\section{ВКЛАД ПОВТОРНЫХ СОЮЗОВ В РОЖДАЕМОСТЬ УВЕЛИЧИЛСЯ}

Анализ панельных данных РиДМиЖ показывает, что вклад повторных союзов в рождения первой, второй и более высокой очередностей значительно увеличился. Если в середине 1950-х годов менее $2 \%$ от всех детей были рождены в повторном союзе, то в первом десятилетии XXI века уже каждый десятый первенец появился в повторном брачнопартнерском союзе, а среди рождений второй и третьей очередностей доля рождений в повторных союзах составила 24 и 43\% соответственно (таблица 3 ).

Таблица 3. Доля рождений в первом и повторном союзе в общем числе рождений первой и более высоких очередностей по порядку и году рождения ребенка, \%

\begin{tabular}{|c|c|c|c|c|c|c|}
\hline \multirow{2}{*}{ Союз } & \multicolumn{6}{|c|}{ Годы рождения детей } \\
\hline & $1950-1959$ & 1960-1969 & $1970-1979$ & 1980-1989 & 1990-1999 & $2000-2009$ \\
\hline \multicolumn{7}{|c|}{ Рождения первой очередности } \\
\hline Первый & 99,6 & 98,0 & 98,2 & 96,8 & 95,6 & 89,1 \\
\hline Повторный & 0,4 & 2,0 & 1,8 & 3,2 & 4,4 & 10,9 \\
\hline \multicolumn{7}{|c|}{ Рождения второй очередности } \\
\hline Первый & 98,6 & 93,7 & 88,9 & 87,9 & 81,1 & 75,9 \\
\hline Повторный & 1,4 & 6,3 & 11,1 & 12,1 & 18,9 & 24,1 \\
\hline \multicolumn{7}{|c|}{ Рождения третьей очередности } \\
\hline Первый & 100,0 & 93,2 & 77,1 & 73,5 & 75,0 & 57,1 \\
\hline Повторный & 0,0 & 6,8 & 22,9 & 26,5 & 25,0 & 42,9 \\
\hline
\end{tabular}

В анализ включены женщины 1930-1986 годов рождения.

Источник: расчеты авторов на основе панельных данных РиДМиЖ-2004, 2007, 2011.

Рождения детей в повторном союзе были наименее распространены среди женщин из поколений 1930-1939 гг. (таблица 4). Однако женщины из этих поколений в большей степени, чем послевоенные поколения, столкнулись с ограничениями в бракоразводном законодательстве и возможностях регистрации ребенка, рожденного вне брака, по совместному заявлению вместе с отцом ребенка.

Рождения первенцев по-прежнему чаще происходят в первом брачно-партнерском союзе. Несмотря на то, что почти 7\% первых детей у женщин из поколений 1980-1986 гг. рождения родились в повторном союзе и эта доля в 2 раза выше, чем у женщин 1950-х годов 
рождения, говорить о высокой значимости вклада повторных союзов в рождения первой очередности пока оснований нет.

Таблица 4. Доля рождений в первом и повторном союзе по порядку рождения и поколениям женщин, \%

\begin{tabular}{|c|c|c|c|c|c|c|}
\hline \multirow[t]{2}{*}{ Союз } & \multicolumn{6}{|c|}{ Годы рождения женщин } \\
\hline & $1930-1939$ & 1940-1949 & 1950-1959 & 1960-1969 & 1970-1979* & 1980-1986* \\
\hline \multicolumn{7}{|c|}{ Рождения первой очередности } \\
\hline Первый & 97,9 & 97,7 & 96,3 & 97,5 & 95,6 & 93,1 \\
\hline Повторный & 2,1 & 2,3 & 3,7 & 2,5 & 4,5 & 6,9 \\
\hline \multicolumn{7}{|c|}{ Рождения второй очередности } \\
\hline Первый & 93,5 & 88,3 & 84,8 & 87,3 & 81,0 & 78,6 \\
\hline Повторный & 6,5 & 11,7 & 15,2 & 12,7 & 19,0 & 21,4 \\
\hline \multicolumn{7}{|c|}{ Рождения третьей очередности } \\
\hline Первый & 89,4 & 75,0 & 73,0 & 78,8 & 61,4 & 66,7 \\
\hline Повторный & 10,6 & 25,0 & 27,0 & 21,2 & 38,6 & 33,3 \\
\hline
\end{tabular}

Источник: расчеты авторов на основе панельных данных РиДМиЖ-2004, 2007, 2011.

В то же время вклад повторных союзов в рождаемость вторых и третьих детей в России постепенно становится все более существенным. Для всех поколений женщин 19401969 гг. характерна примерно одинаковая доля рождений детей второй и третьей очередности, появившихся на свет в повторных союзах (12-15\% для вторых и 21-27\% для третьих детей). В то время как для поколений женщин, родившихся в 1970-е и 1980-е годы, несмотря на то, что они еще не закончили свою репродуктивную биографию, следует ожидать значимо большую долю рождений вторых и третьих детей в повторных союзах. Согласно текущей оценке, вклад повторных союзов сегодня составляет более $21 \%$ от общего числа вторых и более $33 \%$ от всех третьих детей в России.

\section{ВТОРЫЕ ДЕТИ ЧАЩЕ РОЖДАЮТСЯ В НЕФОРМАЛЬНЫХ СОЮЗАХ}

Учитывая высокий процент незарегистрированных повторных браков, нами была выдвинута гипотеза о том, что вторые рождения чаще будут происходить в неформальных союзах. Эта гипотеза находит подтверждение на данных РиДМиЖ. За рассматриваемый период с 1950 до 2009 г. доля вторых рождений в первых незарегистрированных союзах увеличилась с 11 до 42\%, т.е. приблизилась к половине от всех вторых рождений в первых союзах (таблица 5). Среди вторых рождений в повторных союзах уже давно большинство происходит в неформальных супружеских союзах, а не в официальном браке, и в настоящий момент вклад сожительств превышает $80 \%$ от общего числа детей второй очередности в повторных союзах.

Перспектива наступления беременности и рождения ребенка в повторном неформальном союзе усиливает мотивацию заключить официальный брак между партнерами, однако, по-видимому, традиционная нормативная обязательность легализации супружеских отношений в российском обществе даже в этом случае разделяется далеко не всеми. По данным Выборочного наблюдения репродуктивных планов населения за 2012 г. $28,2 \%$ женщин, состоящих в повторном супружеском союзе, не намерены регистрировать брак, если у них наступит беременность, и 22,9\% не будут регистрировать брак, даже если 
у них родится ребенок [Аналитический отчет... 2013]. По сравнению с долей респондентов, считающих регистрацию повторного союза обязательной процедурой в общем случае (см. данные, приведенные выше), отличия минимальны. В современном обществе деторождение, очередность супружеского союза и степень его легитимности не обладают жесткой сцепленностью и взаимной детерминированностью. В то же время можно ожидать, что, чем большую распространенность будут приобретать устойчивые неформальные союзы, тем больше будет доля детей, рожденных в таких союзах. Причем для вторых по очередности детей у матери, рожденных в ее повторном союзе, шансы появится на свет у родителей, состоящих в официальном браке, существенно ниже, чем в супружеском союзе, основанном на неформальных отношениях.

Таблица 5. Распределение вторых рождений по году, типу и очередности союза у матери, \%

\begin{tabular}{l|r|r|r|r|r|r}
\hline \multirow{2}{*}{ Тип союза } & \multicolumn{5}{c}{ Годы рождения детей } \\
\cline { 2 - 7 } & $1950-1959$ & $1960-1969$ & $1970-1979$ & $1980-1989$ & $1990-1999$ & $2000-2009$ \\
\hline & 88,6 & 79,1 & 76,9 & 78,0 & 70,3 & 58,1 \\
Брак & 11,4 & 20,9 & 23,1 & 22,0 & 29,7 & 41,9 \\
Незарегистрированный союз & \multicolumn{7}{c}{ Повторные союзы } \\
Брак & 100,0 & 23,5 & 38,1 & 39,2 & 22,7 & 17,0 \\
Незарегистрированный союз & 0,0 & 76,5 & 61,9 & 60,8 & 77,3 & 83,0 \\
\hline
\end{tabular}

В анализ включены женщины 1930-1986 годов рождения.

Источник: расчеты авторов на основе панельных данных РиДМиЖ-2004, 2007, 2011.

\section{ВКЛАД ПОВТОРНЫХ СОЮЗОВ В ИТОГОВУЮ РОЖДАЕМОСТЬ ЖЕНЩИН С РАЗЛИЧНЫМ ОПЫТОМ БРАЧНО-ПАРТНЕРСКИХ ОТНОШЕНИЙ}

Анализ накопленной итоговой рождаемости женщины к определенному возрасту показывает, что систематических отличий и значимой разницы по среднему числу детей, рожденных женщиной к возрасту 40 лет, между состоящими в непрерывном брачнопартнерском союзе и состоящими в повторном союзе нет (таблицы 6, 7). Непрерывность супружеского союза не является непременным условием для реализации женщиной своих репродуктивных намерений и идеала двухдетной семьи.

Итоговая рождаемость женщин поколений 1930-1969 гг., состоявших до возраста 40 лет в непрерывном брачно-партнерском союзе, по своим значениям близка к идеалу двухдетной семьи (таблица 7).

Распад супружеского союза в случае вступления женщины в новый брачнопартнерский союз во всех рассматриваемых поколениях женщин, кроме поколений 19301939 гг. рождения, не снижал ее шансы на рождение такого же числа детей, какое у нее было бы в случае непрекращения первого супружеского союза. Итоговая рождаемость женщин из поколений 1930-1939 гг. разошедшихся с партнером и вступивших в повторный союз, тем не менее значимо меньше, чем итоговое число рождений на 1 женщину, состоявшую в непрерывном супружеском союзе. Это может быть связано с меньшими шансами женщин из этих поколений вступить в повторный союз, и, как следствие, более низкой вероятностью родить ребенка в повторном союзе. 
Таблица 6. Накопленная итоговая рождаемость к возрасту женщины 25, 30, 35 и 40 лет по поколениям женщин и очередности союза рождения второго ребенка, среднее число рождений на одну женщину

\begin{tabular}{l|c|c|c|c}
\hline Годы рождения женщин & К возрасту 25 лет & К возрасту 30 лет & К возрасту 35 лет & К возрасту 40 лет \\
\hline \multicolumn{5}{|c}{ Второй ребенок рожден в непрерывном первом союзе } \\
$1930-1939$ & 0,96 & 1,58 & 1,91 & 2,02 \\
$1940-1949$ & 0,89 & 1,55 & 1,85 & 1,91 \\
$1950-1959$ & 0,97 & 1,59 & 1,90 & 1,97 \\
$1960-1969$ & 1,20 & 1,70 & 1,86 & 1,92 \\
$1970-1979$ & 1,12 & 1,49 & \\
$1980-1986$ & 1,01 & \multicolumn{3}{c}{} \\
$1930-1939$ & Второй ребенок рожден в повторном союзе & 2,01 \\
$1940-1949$ & 0,93 & 1,50 & 1,84 & 2,19 \\
$1950-1959$ & 1,07 & 1,61 & 1,02 & 1,83 \\
$1960-1969$ & 1,11 & 1,58 & 1,72 & \\
$1970-1979$ & 1,20 & 1,59 & & \\
$1980-1986$ & 1,18 & 1,53 & & \\
\hline
\end{tabular}

Источник: расчеты авторов на основе панельных данных РиДМиЖ-2004, 2007, 2011.

Таблица 7. Итоговая рождаемость женщин 1930-1969 годов рождения к возрасту 40 лет в зависимости от их брачно-партнерской истории, среднее число рождений на одну женщину

\begin{tabular}{|c|c|c|c|c|}
\hline \multirow[b]{2}{*}{ Брачно-партнерская история } & \multicolumn{4}{|c|}{ Годы рождения женщин } \\
\hline & $\begin{array}{c}1930- \\
1939\end{array}$ & $\begin{array}{l}1940- \\
1949\end{array}$ & $\begin{array}{c}1950- \\
1959\end{array}$ & $\begin{array}{l}1960- \\
1969\end{array}$ \\
\hline \multicolumn{5}{|c|}{ Первый ребенок рожден в первом брачно-партнерском союзе } \\
\hline Непрерывный брачно-партнерский союз до возраста 40 лет & 2,00 & 1,90 & 1,94 & 1,88 \\
\hline $\begin{array}{l}\text { Первый брачно-партнерский союз распался, женщина вступила } \\
\text { в новый брачно-партнерский союз }\end{array}$ & 1,77 & 2,25 & 2,13 & 1,82 \\
\hline $\begin{array}{l}\text { Первый брачно-партнерский союз распался, женщина не } \\
\text { вступила в новый брачно-партнерский союз }\end{array}$ & 1,79 & 1,72 & 1,64 & 1,57 \\
\hline \multicolumn{5}{|c|}{ Первый ребенок рожден вне брачно-партнерского союза } \\
\hline Женщина вступила в брачно-партнерский союз & 2,54 & 2,09 & 2,07 & 1,81 \\
\hline Женщина не вступила в брачно-партнерский союз & 2,03 & 1,70 & 1,73 & 1,51 \\
\hline
\end{tabular}

Рождение первенца вне брачно-партнерского союза для этих же поколений женщин не означало снижения их шансов на двухдетную семью. Примечательно, что идеала двухдетной семьи в этом случае достигали как матери внебрачных детей, которые вступили впоследствии в брачно-партнерский союз, так и те, кому не удалось создать супружеский союз.

Матери, рожденные в 1940-х, 1950-х годах и имевшие опыт пребывания в нескольких союзах, в итоге родили в среднем большее число детей, чем женщины из этих же поколений, состоявшие в непрерывном супружеском союзе. Для поколений женщин 1960-х годов рождения статистически значимых различий в итоговом числе детей между состоявшими в непрерывном супружеском союзе и вступившими в повторный союз не обнаружено.

Для поколений женщин 1940-1969 гг., которые не смогли после распада первого союза или рождения ребенка вне брачно-партнерского союза вступить в супружеский союз, итоговое число рожденных детей в среднем меньше на 0,2-0,3 ребенка на женщину, и это 
различие статистически значимо. Отметим также, что итоговая рождаемость женщин, переживших распад первого союза и не вступивших в повторный союз, статистически не отличается от рождаемости женщин, родивших первенца вне супружеского союза. Это означает, что неудача в поиске партнера сделала идеал двухдетной семьи для женщин из этих поколений труднодостижимым.

\section{Выводы}

Таким образом, повторные союзы играют важную роль в реализации репродуктивных установок. Вступление в повторный союз позволяет компенсировать не только распад первого союза с точки зрения общего времени, проведенного в статусе супруга/супруги в течение всей жизни, но и компенсировать дефицит рождений, который образуется у индивидов, пребывающих в предразводном или послеразводном состоянии. Повторные союзы часто официально не регистрируются, однако это обстоятельство не мешает супругам реализовывать свои репродуктивные намерения. Вступление в незарегистрированный повторный союз, так же, как и в зарегистрированный, повышает для женщины вероятность иметь двоих и последующих детей, тем самым обеспечивая возможность соответствовать социальной норме, при которой стремление к идеалу двухдетной семьи высоко значимо. Однако успешность поиска нового партнера для женщины репродуктивного возраста является ключевым фактором, определяющим то число детей, которое она может родить.

Вклад рождений в повторных союзах в общее число рождений непрерывно увеличивался в рассматриваемый период между 1950-2009 гг. Проведенный анализ показал, что существуют значительные различия между поколениями женщин в возможностях достижения ими идеала двухдетной семьи после распада повторного союза. Но остается открытым вопрос, какие факторы, а также демографические и социальноэкономические характеристики обоих партнеров во вновь образовавшемся супружеском союзе влияют на вероятность рождения ребенка в этом союзе.

\section{ЛИТЕРАТУРА}

Аналитический отчет по итогам выборочного наблюдения репродуктивных планов населения (2013). М.: Федеральная служба государственной статистики. URL: http://www.gks.ru/free_doc/2012/demo/orp.doc (дата обращения 10.02.2016).

Архангельский В.Н. (2005). II.1. Репродуктивные ориентации. II.2 Матримониальные ориентации // В.Н. Архангельский, В.В. Елизаров, Н.В. Зверева, Л.Ю. Иванова. Демографическое поведение и его детерминация (по результатам социологодемографического исследования в Новгородской области). М.: ТЕИС: 49-72.

(2006). Факторы рождаемости. М.: ТЕИС.

Белова В., Л. Дарский (1987). Рождаемость в повторных браках: По материалам выборочных обследований // Вестник статистики. №7: 35-43.

Белова В.А. (1983). Повторные браки и рождаемость //Социальный и демографический аспекты исследования брака, семьи и репродуктивных установок. Всесоюзная научная 
конференция «Доходы и потребление семей». 30 мая - 2 июня 1983. Тезисы докладов. Ереван: 13-14.

Белова В.А., Е.М. Морева (1988). Повторные браки женщин: ситуация и факторы //Методология демографического прогноза / Отв. ред. А.Г. Волков. М.: Наука:100-117.

Бодрова В. (2002). Сколько детей хотят иметь россияне? // Демоскоп Weekly. №81-82. URL: http://demoscope.ru/weekly/2002/081/tema03.php (дата обращения: 10.02.2016).

Борисов В.А. (2007). Демографическая дезорганизация России: 1897-2007 // Избранные демографические труды / Редактор-составитель А.И. Антонов. М.: "NOTA BENE".

Вишневский А.Г., М.С. Тольц (1988). Эволюция брачности и рождаемости в советский период //Население СССР за 70 лет / Отв. ред. Л.Л. Рыбаковский. М.: Наука: 75-114.

Голод С.И. (1998). Семья и брак: историко-социологический анализ. СПБ: ТОО ТК «Петрополис».

Гурко Т.А. (2003). Родительство: социологические аспекты. М.: Центр общечеловеческих ценностей.

(2008). Брак и родительство в России. М.: Институт социологии РАН.

Захаров С.В. (2007a). Новейшие тенденции формирования семьи в России //Мир России. T.XVI. №4: 73-112.

---------- (2007b). Трансформация брачно-партнерских отношений в России: «золотой век» традиционного брака близится к закату? //Родители и дети, мужчины и женщины в семье и обществе. По материалам одного исследования. Сб. аналитических статей. Вып.1. / Научн. ред. Т.М. Малева, О.В. Синявская. М.: НИСП: 75-126.

(2009). Браки и разводы // Население России 2007: Пятнадцатый ежегодный демографический доклад / Отв. ред. А.Г. Вишневский. М.: Изд. дом ВШЭ.

Зверева Н.В. (2012). Уровень жизни семьи как общее условие детерминации демографических процессов //Детерминация демографических процессов. Сб. статей / Под ред. Н.В. Зверевой, В.Н. Архангельского. М.: МАКС Пресс: 30-57.

Малева Т.М., А.О. Тындик (2014). Потенциал роста рождаемости в Москве // Демоскоп Weekly. №585-586. URL: http://demoscope.ru/weekly/2014/0585/tema01.php (дата обращения: 10.02.2016).

Тольц М.С. (1986а). Демографический анализ брачности: проблемы, методы, интерпретация результатов // Методы исследования /Рук. авт. кол. А.Г. Вишневский. М.: Мысль: 79-95.

----------- (1986b). Взаимосвязи брачного и репродуктивного поведения // Детность семьи: вчера, сегодня, завтра / Рук. авт. кол. А.И. Антонов. М.: Мысль: 39-53.

Тындик А.О. (2012). Репродуктивные установки населения в современной России // SPERO. Социальная политика: экспертиза, рекомендации, обзоры. №16 (Весна-лето): 95-112.

Beaujouan E., A. Solaz (2008). Childbearing after separation: do second unions make up for missing births? Evidence from France. Documents de travail. №155. Paris: INED.

Güntter I., K. Harttgen (2016). Desired fertility and number of children born across time and space // Demography. 53(1): 55-83.

Henz U., E. Thomson (2005). Union stability and stepfamily fertility in Austria, Finland, France and West Germany //European Journal of Population. 21: 3-29. 
Kreyenfeld M., V. Heintz-Martin (2015). Fertility after separation: second births in higher order unions in Germany // Family and Societies Working Paper Series 'Changing families and sustainable societies: Policy contexts and diversity over the life course and across generations'. №28.

Levin I. (2004). Living apart together: a new family form // Current Sociology. 52(2): 223-240

Prskawetz A., A. Vikat, D. Philipov, H. Engelhardt (2003). Pathways to stepfamily formation in Europe: results from the FFS // Demographic Research. 8: 107-150.

Testa M.R. (2012). Family sizes in Europe: evidence from the 2011 Eurobarometer Survey. // European Demographic Research Papers. №2. Vienna Institute of Demography.

Thomson E. (2004). Step-families and childbearing desires in Europe //Demographic Research (Special Collection 3): 117-134.

Thomson E., M. Winkler-Dworak, M. Spielauer, A. Prskawetz (2009). Union instability as an engine of fertility? A micro-simulation model for France // Working Papers. №2. Vienna Institute of Demography.

Thomson E., T. Lappegård, M. Carlson, A. Evans, E. Gray (2014). Childbearing across partnerships in Australia, the Unites States, Norway and Sweden // Demography. 51: 485508.

Vikat A., E. Thomson, J.M. Hoem (1999). Stepfamily fertility in contemporary Sweden: the impact of childbearing before the current union //Population Studies. 53: 211-225. 


\title{
FERTILITY IN HIGHER-ORDER MARITAL UNIONS IN RUSSIA: DOES A NEW PARTNERSHIP ALLOW FOR THE REALIZATION OF THE TWO-CHILD IDEAL?
}

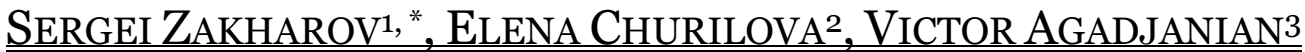

\begin{abstract}
The rapid deinstitutionalization of lifetime marriage in developed countries in the second half of the 20th century has resulted in increased proliferation and acceptability of diverse forms of marital unions. On the one hand, all developed countries have seen rising risks of dissolution of first marriages; on the other hand, this trend has been partly compensated by increases in second and subsequent unions. The demographic consequences of these fundamental social shifts in Russia have not yet been well studied. In particular, the contribution of higher-order unions to completed cohort fertility has not been adequately addressed, especially outside western settings. In this article, recent data from the longitudinal Generations and Gender Survey conducted in the Russian Federation were used to examine fertility in higher-order unions (marriages and cohabitations) among the post-war generations. The article contributes to the debate on the persistence of the two-child ideal in contemporary Europe by demonstrating how childbearing in higher-order unions corresponds to or deviates from this ideal in Russia.
\end{abstract}

The results of the study show that higher-order unions play an important role in fulfilling reproductive aspirations. The contribution of births in such unions to the total number of births rose continuously during the observation period of 1950-2009. Entering a higher-order union makes it possible to compensate for the deficit of births that occurs at the pre-divorce and post-divorce stages. Although higher-order unions often are not registered officially, this does not prevent partners from carrying out their reproductive intentions. Entry into a higher-order union, whether registered or not, increases the probability that a woman will have two or more children, thus offering the possibility to conform to the social norm of the two-child family. However, for divorced women of reproductive age, success in finding a new partner remains a key factor determining the number of children they have.

Key words: marriage, cohabitation, higher-order unions, fertility, two-child ideal, Russian Generations and Gender Survey, UNECE Generation and Gender Project.

\section{REFERENCES}

Analiticheskii otchet po itogam vyborochnogo nabludenia reproductivnykh planov naselenia [Analytical report on the results of the sample survey of the reproductive plans of population] (2013). Moscow: Federalnaya sluzhba gosudarstvennoi statistiki [Federal state statistics service]. URL: http://www.gks.ru/free_doc/2012/demo/orp.doc (accessed: 10.02.2016).

\footnotetext{
1 National Research University Higher School of Economics (Russia); 2 New Economic School (Russia); 3 UNIVERSITY OF KANSAS (USA).

* Correspondence: szakharov@hse.ru

DATE RECEIVED: December 2015.
}

THE PAPER WAS PREPARED WITHIN THE FRAMEWORK OF THE ACADEMIC FUND PROGRAM AT THE NATIONAL RESEARCH UNIVERSITY HIGHER SCHOOL OF ECONOMICS (HSE) IN 2014-2O15 (GRANT NO14-O5-OO54 "STUDYING OF THE DYNAMICS OF FORMATION AND DEVELOPMENT OF FAMILIES AND FERTILITY USING DATA OF SELECTIVE SURVEYS") AND SUPPORTED WITHIN THE FRAMEWORK OF A SUBSIDY GRANTED TO THE HSE BY THE GOVERNMENT OF THE RUSSIAN FEDERATION FOR THE IMPLEMENTATION OF THE GLOBAL COMPETITIVENESS PROGRAM. 
Arkhangelsky V.N. (2005). II.1.Reproductivnye orientaci. II.2 Matrimonialnye orientacii [II.1. Reproductive attitudes. II.2 Matrimonial attitudes] // V.N. Arkhangelsky, V.V. Elizarov, N.V. Zvereva, L.Yu. Ivanova. Demographicheskoe povedenie i ego determinacia (po rezultatam sociologo-demograficheskogo issledovania v Novgorodskoi oblasti) [Demographic behavior and its determination]. Moscow: TEIS: 49-72. (2006). Faktory rozhdaemosti [Factors of fertility]. Moscow: TEIS.

Beaujouan E., A. Solaz (2008). Childbearing after separation: do second unions make up for missing births? Evidence from France. Documents de travail. №155. Paris: INED.

Belova V., L. Darsky (1987). Rozhdaemost' v povtornykh brakakh [Fertility in higher order marriages]: Results of sample surveys // Vestnik statistiki [Herald of Statistics]. №7: 35-43.

Belova V.A. (1983). Povtornye braki i rozhdaemost' [Remarriages and fertility] //Socialnyi i demograficheskii aspeky issledovania braka, sem'i i reproduktivnykh ustanovok. Vsesouznaya nauchnaya konferencia «Dokhody i potreblenie semei» [Social and demographic aspects of study of marriage, family and reproductive attitudes. All-union scientific conference 'Income and family consumption']. 30 May - 2 June. Abstracts of papers. Erevan: 13-14.

Belova V.A., E.M. Moreva (1988). Povtornye braki zhenshin: situatcia i faktory [Higher order marriages of women: situation and factors] //Metodologia demograficheskogo prognoza [Methodology of demographic projections] / A.G.Volkov, ed. Moscow: Nauka: 100-117.

Bodrova V. (2002). Skolko detei khotyat imet' rossiane [How many children do Russians want ?] // Demoscope Weekly. №81-82. URL:

http://demoscope.ru/weekly/2002/081/tema03.php (accessed: 10.02.2016).

Borisov V.A. (2007). Demograficheskaya dezorganizacia Rossii: 1897-2007 [Demographic disorganization of Russia: 1897-2007]. Selected demographic publications. Ed. and compiled by A.I. Antonov. Moscow: "NOTA BENE".

Golod S.I. (1998). Sem'a i brak: istoriko-sotciologicheskii analiz [Family and marriage: historical and sociological analysis]. Saint Petersburg: TOO TK «Petropolis».

Güntter I., K. Harttgen (2016). Desired fertility and number of children born across time and space // Demography. 53(1): 55-83.

Gurko T.A. (2003). Roditelstvo: sociologicheskie aspekty [Parenthood: sociological aspects]. Moscow: Tcentr obshechelovecheskikh tcennostei.

(2008). Brak i roditelstvo v Rossii [Marriage and parenthood in Russia]. Moscow: RAS Institute of Sociology.

Henz U., E. Thomson (2005). Union stability and stepfamily fertility in Austria, Finland, France and West Germany // European Journal of Population. 21: 3-29.

Kreyenfeld M., V. Heintz-Martin (2015). Fertility after separation: second births in higher order unions in Germany. Family and Societies Working Paper Series 'Changing families and sustainable societies: Policy contexts and diversity over the life course and across generations'. №28.

Levin I. (2004). Living apart together: a new family form //Current Sociology. 52(2): 223-240.

Maleva T.M., A.O. Tyndik (2014). Potenctial rosta rozhdaemosti v Moskve [The potential for increasing fertility in Moscow] // Demoscope Weekly. №585-586. URL:

http://demoscope.ru/weekly/2014/0585/tema01.php (accessed: 10.02.2016). 
Prskawetz A., A. Vikat, D. Philipov, H. Engelhardt (2003). Pathways to stepfamily formation in Europe: results from the FFS //Demographic Research. 8: 107-150.

Testa M.R. (2012). Family sizes in Europe: evidence from the 2011 Eurobarometer Survey. 2012. European Demographic Research Papers. №2. Vienna Institute of Demography.

Thomson E. (2004). Step-families and childbearing desires in Europe //Demographic Research (Special Collection 3): 117-134.

Thomson E., M. Winkler-Dworak, M. Spielauer, A. Prskawetz (2009). Union instability as an engine of fertility? A micro-simulation model for France. Working Papers. № 2. Vienna Institute of Demography.

Thomson E., T. Lappegård, M. Carlson, A. Evans, E. Gray (2014). Childbearing across partnerships in Australia, the Unites States, Norway and Sweden //Demography. 51: 485508.

Tolts M.S. (1986a). Demograficheskii analiz brachnosti: problemy, metody, interpretactia rezultatov [Demographic analysis of nuptiality: problems, methods, interpretation of results] // Metody issledovanii [Research methods] / A.G. Vishnevsky, ed. Moscow: Mysl': 79-95.

(1986b). Vzaimosvyaz' brachnogo i reproductivnogo povedenia [Relationship between matrimonial and reproductive behaviors] //Detnost' sem'i: vchera, segodnya, zavtra [Number of children in a family: yesterday, today, and tomorrow] / A.I. Antonov, ed. Moscow: Mysl': 39-53.

Tyndik A.O. (2012). Reproduktivnye ustanovki naselenia v sovremennoi Rossii [Reproductive attitudes of population in contemporary Russia] // SPERO. Social Policy: Expertise, Recommendations, Overviews. №16 (Spring-Summer): 95-112.

Vikat A., E. Thomson, J.M. Hoem (1999). Stepfamily fertility in contemporary Sweden: the impact of childbearing before the current union // Population Studies. 53: 211-225.

Vishnevsky A.G., M.S. Tolts (1988). Evolutcia brachnosti i rozhdaemosti v sovetskii period [Evolution of nuptiality and fertility in the Soviet period] //Naselenie SSSR za 70 let [Population of the USSR for 70 years] / L.L. Rybakovsky, ed. Moscow: Nauka: 75-114.

Zakharov S.V. (2007a). Noveishie tendentcii formirovania sem'i v Rossii [New tendencies in family formation in Russia] //Mir Rossii (Universe of Russia).Vol.XVI (4): 73-112.

---------- (2007b). Transformatcia brachno-partnerskikh otnoshenii v Rossii: 'zolotoi vek' tradictionnogo braka blizitcya k zakatu? [Transformation of partnerships in Russia: is the 'golden age' of marriage coming to the end?] // Roditeli i deti, muzhchiny i zhenshiny $\mathrm{v}$ sem'e i obshetsve [Parents and Children, Men and Women in Family and Society]. Issue 1/ T.M.Maleva, O.V.Sinyavskaya, eds. Moscow: Independent Institute for Social Policy: 75126.

(2009). Braki i razvody [Marriages and divorces] //Naselenie Rossii 2007 [Population of Russia 2007]: fifteenth annual analytical report / A.G. Vishnevsky, ed. Moscow: HSE Publishing House.

Zvereva N.V. (2012). Uroven' zhizni sem'i kak obshee uslovie determinatcii demograficheskih protcessov [Living standards of family as a general condition for demographic process] // Determinatcia demograficheskikh protcessov [Determination of demographic process] / N.V.Zvereva, V.N.Arkhangelsky, ed. Moscow: MAKS Press: 30-57. 